\title{
Systemic vitamin intake impacting tissue proteomes
}

\author{
Heesoo Jeong and Nathaniel M. Vacanti ${ }^{*}$ (])
}

\begin{abstract}
The kinetics and localization of the reactions of metabolism are coordinated by the enzymes that catalyze them. These enzymes are controlled via a myriad of mechanisms including inhibition/activation by metabolites, compartmentalization, thermodynamics, and nutrient sensing-based transcriptional or post-translational regulation; all of which are influenced as a network by the activities of metabolic enzymes and have downstream potential to exert direct or indirect control over protein abundances. Considering many of these enzymes are active only when one or more vitamin cofactors are present; the availability of vitamin cofactors likely yields a systems-influence over tissue proteomes. Furthermore, vitamins may influence protein abundances as nuclear receptor agonists, antioxidants, substrates for post-translational modifications, molecular signal transducers, and regulators of electrolyte homeostasis. Herein, studies of vitamin intake are explored for their contribution to unraveling vitamin influence over protein expression. As a body of work, these studies establish vitamin intake as a regulator of protein abundance; with the most powerful demonstrations reporting regulation of proteins directly related to the vitamin of interest. However, as a whole, the field has not kept pace with advances in proteomic platforms and analytical methodologies, and has not moved to validate mechanisms of regulation or potential for clinical application.
\end{abstract}

Keywords: Proteomics, Big data, Vitamin, Metabolism, Precision nutrition, Molecular nutrition

\section{Introduction}

\section{Regulatory Mechanisms}

Cellular metabolism is a system of chemical reactions in which cells harness the energy stored in the chemical bonds of substrate molecules to perform their biological functions, maintain homeostasis, or to synthesize building blocks for structural maintenance or cellular division. The kinetics of these reactions are dependent on the activity of the proteins which catalyze them; thus proteins are key modulators of metabolism.

Metabolic activity also exerts network control over itself by a diverse array of mechanisms which finely tune protein expression responses via nutrient sensing machineries [1]. Products or intermediates of a metabolic pathway can inhibit or activate metabolic enzymes; e.g. malate inhibits the succinate dehydrogenase complex [2] and fructose-

\footnotetext{
* Correspondence: nv83@cornell.edu
}

Division of Nutritional Sciences, Cornell University, Ithaca, NY, USA 2,6-bisphosphate activates phosphofructokinase [3]. The oxidative status of a cell can drive the directionality of redox reactions and impact abundances of redox reactioncatalyzing proteins; e.g. the KEAP1/NRF2 network responds to oxidative stress by upregulating expression of antioxidant-functioning proteins [4]. Splice-variant or isozyme expression can impact relative pathway utilization at metabolic network nodes; e.g. splice variants and isozymes of pyruvate and lactate dehydrogenase respectively impact the bridge between glycolysis and the tricarboxylic acid (TCA) cycle [5, 6]. Additionally, local metabolite concentrations and thermodynamics can dictate the directionality of reactions catalyzed by compartment-specific isozymes; e.g. reductive activity of isocitrate dehydrogenase can be confined to the cytosol-specific isozyme [7]. The impacts of the above-mentioned regulations are closely monitored by nutrient sensing proteins which initiate molecular events altering protein activation and expression; e.g. 
serine/threonine kinase 11, AMP-activated protein kinase, mammalian target of rapamycin 1 , and sterol regulatory element-binding protein 1 are part of overlapping protein networks that orchestrate protein-expression and posttranslational modification responses to nutrient availability $[8,9]$. Considering that many metabolic enzymes do not function in isolation and, as detailed in the sections that follow, require vitamin cofactors to stabilize intermediates, donate/accept electrons, shuttle substrates, and hold reactants in close proximity; vitamin status is a critical consideration when examining protein-mediated regulation of metabolism and the impacts of metabolism on protein expression.

In addition to their potential regulatory roles as cofactors, vitamins orchestrate other direct or indirect mechanisms influencing protein abundance. Retinoic acid (vitamin A) interacts with nuclear receptors impacting gene transcription [10], ascorbic acid (vitamin C) impacts oxidative status and associated protein networks [11] and is reported to exhibit epigenetic regulation over protein expression [12], vitamin D regulates calcium signaling machinery, activates nuclear receptors, and exerts hormonal regulation over protein expression [13, 14], and niacin (vitamin $\mathrm{B}_{3}$ ) and biotin (vitamin $\mathrm{B}_{7}$ ) can be incorporated as post-translational modifications impacting protein function $[15,16]$.

Herein, studies on systemic intake (dietary, injection, oral gavage) of vitamins and their impacts on tissue proteomes are examined, and their contributions to unraveling vitamin-based regulation of protein expression and tissue function are explored. The current work is intended to provide background information to understand each vitamin's (Figs. 1 and 2) molecular functions and highlight its role as a cofactor or substrate in the reactions of central metabolism (Fig. 3, Tables S1, S2, S3, S4, S5, S6, S7, S8, S9, S10, S11, S12 and S13). Finally, this work is intended as a resource for identifying regulation of proteins related to vitamin metabolism in published works. The public domain of proteomic data sets is ever expanding, but is rarely searched for effects related to vitamin metabolism. To that end, all proteins are specified by their HUGO Gene Nomenclature Committee (HGNC) gene symbol, or the HGNC gene symbol of the human ortholog when identified in another species, and proteins requiring a vitamin as a cofactor or substrate are tabulated (Tables S1, S2, S3, S4, S5, S6, S7, S8, S9, S10, S11, S12 and S13).

\section{Proteomics Platforms}

Proteomics platforms of the discussed studies are provided to place them on a technological timeline. Platforms are described with the terms: orbitrap, QTOF (quadrupole time-of-flight), triple-TOF (triple - time of flight), QQQ (triple-quadrupole), 2DGE-MS (two-dimensional gel electrophoresis - mass spectrometry), and 2DGE. In brief, orbitrap platforms are the workhorses of modern proteomics because their high achievable mass resolutions combined with high sensitivity are best suited for maximizing the number of proteins identified in a complex sample $[17,18]$; though QTOF and tripleTOF instruments, capable of maintaining mass resolution
Vitamin A

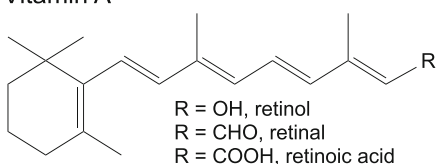

Vitamin E
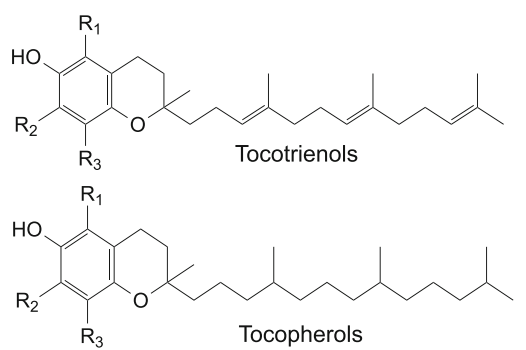

$\mathrm{R} 1, \mathrm{R} 2, \mathrm{R} 3=\mathrm{CH}_{3} \quad$ alpha

$\begin{array}{lr}\mathrm{R} 1, \mathrm{R} 3=\mathrm{CH}_{3} & \text { beta } \\ \mathrm{R} 2, \mathrm{R} 3=\mathrm{CH}_{3} & \text { gamma }\end{array}$

$\mathrm{R} 3=\mathrm{CH}_{3} \quad$ delta
Otherwise R1, R2, R3 $=\mathrm{H}$

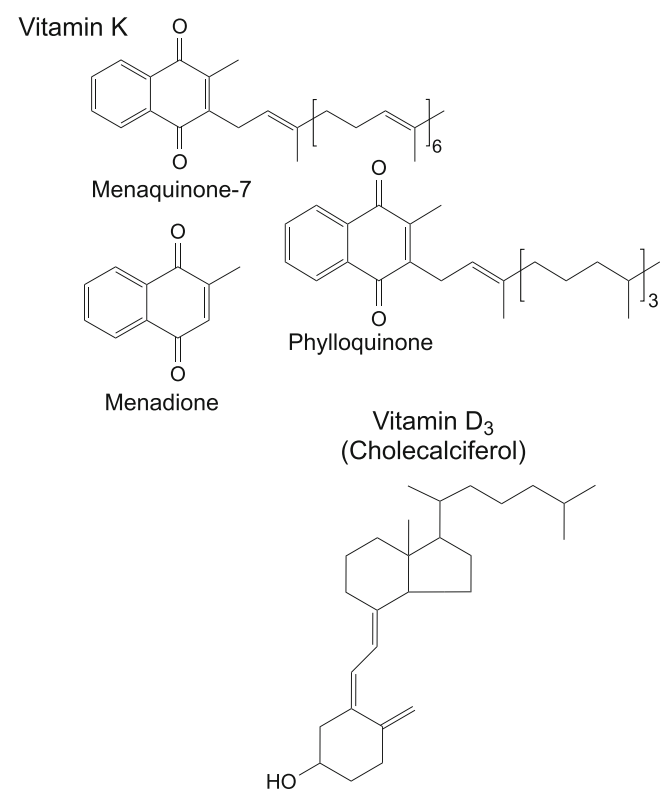

Fig. 1 Fat soluble vitamin structures 


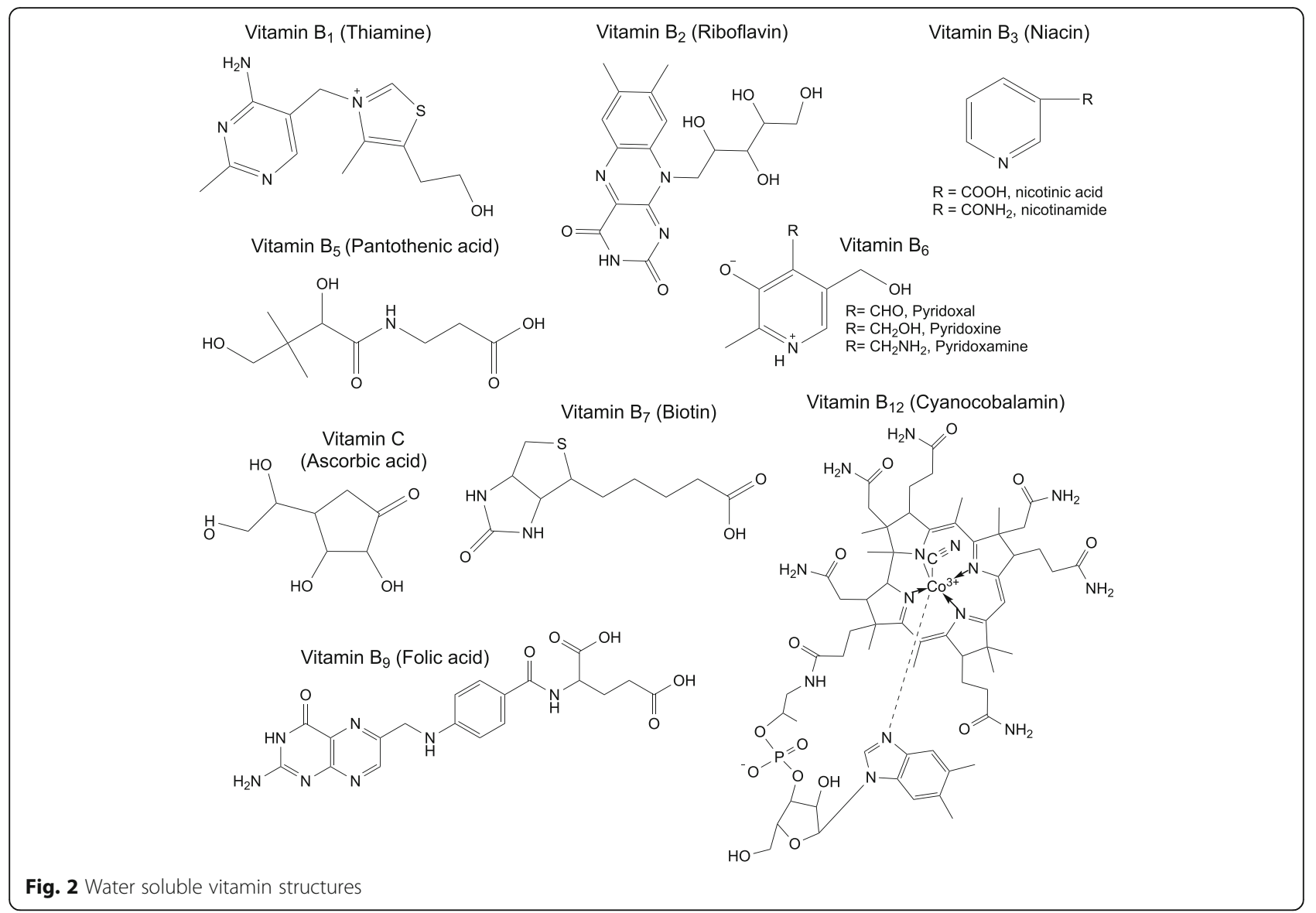

at higher scan speeds [19], hold a substantial influence in this arena. Within the categories of orbitrap, QTOF, and triple-TOF, there are major technological advances not discussed here. QQQ platforms are best suited for quantifying a pre-determined list of proteins. Lower scan speeds and mass resolution render them less capable than orbitrap, QTOF, or triple-TOF systems for non-targeted applications [17]. Advances in nano-flow liquid chromatography coupled directly to mass spectrometry have improved proteomic depth by orders of magnitude over that achievable by 2DGE-MS, where the upstream selection of protein spots predates the modern definition of non-targeted proteomics. Similarly, identifying differentially intense protein spots using 2DGE alone is considered an important milestone in the development of proteomics; but is rarely discussed outside the topic of the field's history.

\section{Vitamin Regulation of Tissue Proteomes Vitamin A}

Vitamin A exists in alcohol, aldehyde, acid, and ester forms known as retinol, retinal, retinoic acid, and retinyl esters respectively (Fig. 1) [20]. Several carotenoids are precursors to vitamin $A$ including $\alpha$ - and $\beta$-carotene
[21]. $\beta$-carotene is converted to two molecules of retinal by beta carotene oxygenases ( $\mathrm{BCO} 1$ or $\mathrm{BCO} 2$ ) [22]. Retinal is an important component of rhodopsin $(R H O)$, a protein in rod cells responsible for detecting low levels of light [23]. Thus night blindness is telltale characteristic of vitamin A deficiency [24]. Retinoic acid serves as a signaling molecule, acting through nuclear retinoic acid (RARA, RARB, RARG) and retinoid X (RXRA, RXRB, $R X R G)$ receptors which regulate growth and differentiation [25, 26]. Cellular and organismal trafficking of vitamin $\mathrm{A}$ is dependent on retinol/retinoic acid binding proteins (RBP family, CRABP1, CRABP2) and retinol esterification via lecithin retinol acyltransferase (LRAT) [27]. Retinal is oxidized to retinol via aldehyde dehydrogenases ( $A L D H$ family) and retinol is oxidized to retinoic acid by retinol dehydrogenases ( $R D H$ and DHRS families) [28]. In addition to inducing night blindness, vitamin A deficiency adversely impacts cellular growth, bone development, and antibody-based immune responses [29].

In an orbitrap-based study of mouse embryo heads, toxic levels of prenatal retinoic acid exposure intended to model an established risk factor for craniofacial birth defects are reported to induce abundance alterations in proteins associated with craniofacial development and 


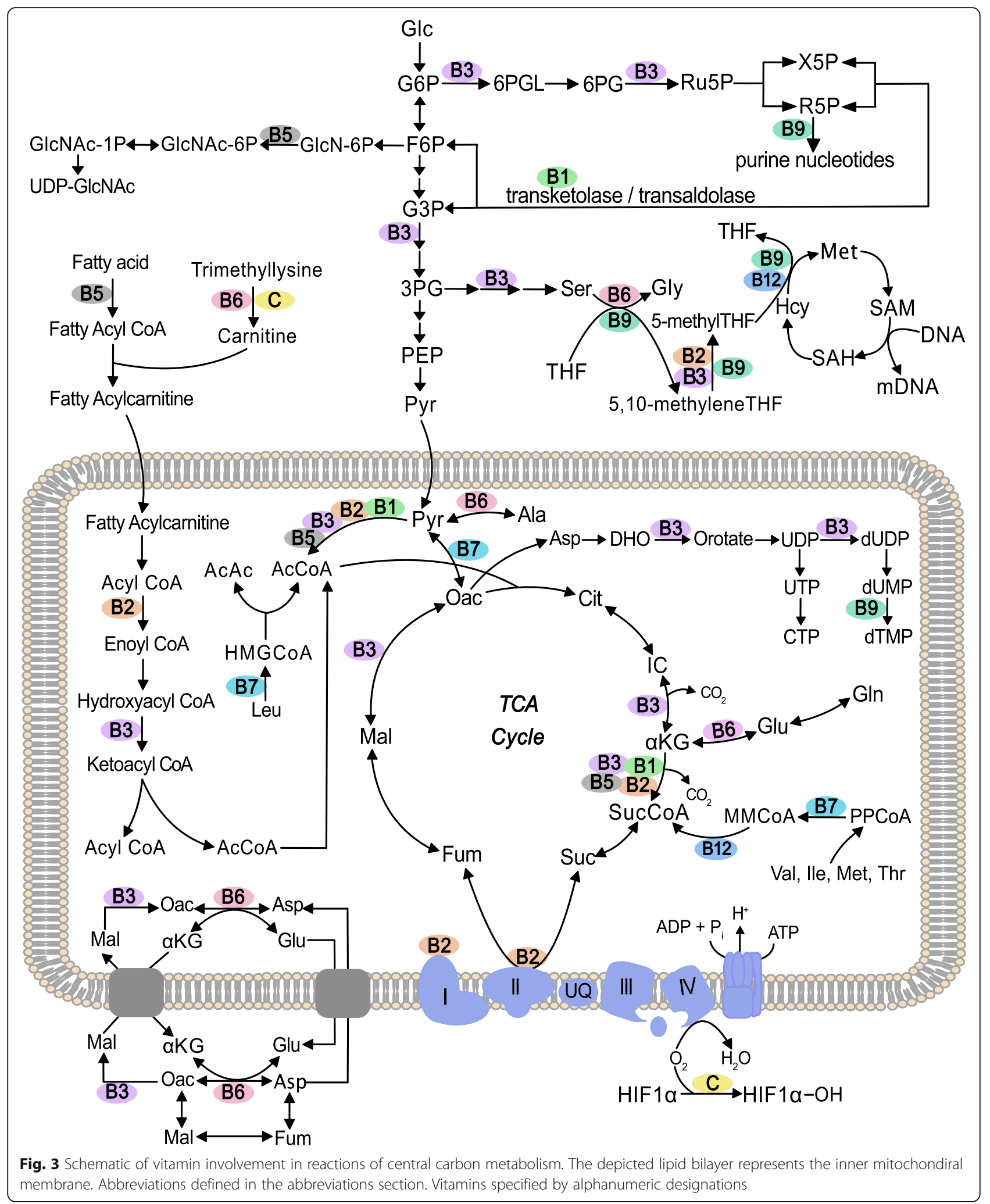


neural crest processes [30]. In a parallel triple-TOFbased study of gerbil plasma and 2DGE-MS-based study of gerbil liver and white adipose tissue, a few dozen protein abundances linked to a handful of biological processes are reported to respond to dietary retinol, $\beta$-carotene, lutein, or lycopene; though process or pathway enrichment analyses are not reported. As the authors discuss, plasma was not depleted of common highly abundant proteins upstream of analysis by mass spectrometry which are known to adversely impact data quality [31]. In an orbitrap-based study of plasma from Nepalese children, dozens of proteins are associated with circulating carotenoid abundances; potentiating development of low-cost antibody-based tests for carotenoid deficiencies [32]. A pair of 2DGE-MS-based studies link tissue function to protein abundance responses to vitamin A status in mice brains [33] and bovine muscle [34].

\section{Vitamin $\mathrm{B}_{1}$}

Thiamine (vitamin $\mathrm{B}_{1}$ ) is composed of linked pyrimidine and thiazole rings decorated with methyl, amine, and alkyl-hydroxyl functional groups (Fig. 2) [35]. Thiamine is transported through the plasma membrane via thiamine transporters (SLC19A2 and SLC19A3) [36] and then twice phosphorylated on the alkyl-hydroxyl functional group by thiamine pyrophosphokinase (TPK1), rendering it active as thiamine diphosphate (TDP) [35]. TDP is a cofactor for enzymes catalyzing the oxidative decarboxylation of ketoacids including the pyruvate dehydrogenase complex (PDHA, PDHB, PDHX, DLAT, $D L D)$, the oxoglutarate dehydrogenase complex $(O G D H$, $D L S T, D L D)$, and the branched chain keto acid dehydrogenase complex (BCKDHA, DBT, DLD) [37]. It is also a cofactor for transketolase (TKT) in the non-oxidative branch of the pentose phosphate pathway [38]. Independent from its role as a cofactor, thiamine is believed to regulate ion transport activity in the nervous system [39].

Vitamin $B_{1}$ deficiency is marked by a broad range of neurological, respiratory, and cardiovascular pathophysiologies and is termed beriberi. Symptoms of beriberi are difficult to directly link to the molecular functions of vitamin $B_{1}[40]$.

In a 2DGE-MS-based study of type 2 diabetic and healthy control subjects, authors report treatment with thiamine reduces albumin $(A L B)$ abundance in urine; indicating the vitamin serves a protective role of kidney function [41]. In a QTOF-based study of rat thalami under thiamine deficiency, glyceraldehyde-3-phosphate dehydrogenase $(G A P D H)$ is the most up-regulated protein (50 fold) while regulated proteins are most enriched in the synaptic vesicle cycle pathway (according to the KEGG database). Proteomic changes are accompanied by diminished performances on cognitive tests [42].

\section{Vitamin $\mathrm{B}_{\mathbf{2}}$}

Riboflavin (vitamin $B_{2}$ ) is composed of an isoalloxazine ring and a bound ribitol (Fig. 2) [43]. It is activated by riboflavin kinase (RFK), forming flavin mononucleotide (FMN); and by flavin adenine dinucleotide synthase 1 (FLAD1), forming flavin adenine dinucleotide (FAD) [44]. Bound FMN or FAD serves as an electron carrier for redox-reaction-catalyzing proteins (flavoproteins) including the succinate dehydrogenase complex ( $S D H A, S D H B, S D H C, S D H D$ ), the pyruvate dehydrogenase complex (PDHA, PDHB, PDHX, DLAT, DLD), acyl-CoA dehydrogenases (ACADs), and methylene tetrahydrofolate reductase (MTHFR) [45].

Riboflavin deficiency in humans predominantly occurs in combination with that of other nutrients. However animal studies link it to impaired fetal and intestinal development [46, 47], iron absorption [48], and lipid metabolism $[49,50]$.

In a QTOF-based study of duck livers, riboflavin deficiency is accompanied by a reduced abundance of smallchain-specific acyl-coenzyme A dehydrogenases (ACADs), for which riboflavin serves as a cofactor, and concordant elevation of hepatic small chain fatty-acid lipid content. Dramatic decreases in protein abundance are reported for INPP1 (involved in inositol signaling), THRSP (purported regulator of lipid metabolism), $B D H 2$ (a regulator of lipid metabolism), $F X N$ (involved in mitochondrial iron-sulfur complex assembly), and NDUFS1 (a subunit of electron transport chain complex I) [51]. In a QTOF-based study of maternal riboflavin deficiency, reductions in fetal duck hepatic TCA cycle, beta-oxidation, and electron transport chain proteins are reported, with $I D H 3 A$ being the lone member of these pathways whose abundance increases [52].

\section{Vitamin $\mathbf{B}_{3}$}

Niacin (vitamin $B_{3}$ ) is inclusive of nicotinic acid and nicotinamide (Fig. 2) which are converted to their mononucleotide forms by nicotinate phosphoribosyltransferase (NAPR $T)$ and nicotinamide phosphoribosyltransferase (NAMPT) respectively [53]. Both forms of the mononucleotide are subsequently converted to their adenosine dinucleotide forms by nicotinamide/nicotinic acid mononucleotide adenylyltransferases (NMNAT1, NMNAT2, NMNAT3). Nicotinamide adenine dinucleotide (NAD) is a cofactor form of the vitamin whereas nicotinic acid dinucleotide is subsequently converted to NAD by NAD synthase (NADS YN1) [54]. NAD is reduced to NADH by oxidative reactions of glycolysis, the TCA cycle, and $\beta$-oxidation; and subsequently serves as a redox equivalent carrier to the electron transport chain [55] and to regenerate reduced ascorbic acid (vitamin C) [56], glutathione [57], and thioredoxin [58]. NAD can also be phosphorylated by NAD kinases (NADK, NADK2) to form a distinct redox shuttling cofactor, NADP [59]. NADP is reduced by reactions in the 
oxidative pentose phosphate pathway (G6PD, PGD) and other enzymes (e.g. ME1, ME3, IDH1, IDH2) to NADPH. $\mathrm{NADPH}$ provides reducing equivalents for biosynthetic reactions in fatty acid, cholesterol, and deoxyribonucleotide synthesis [60]. Outside its role as a reducing equivalent shuttle, NAD provides adenine dinucleotide phosphate (ADP) ribose for synthesis of the second messenger, cyclic adenosine monophosphate (cAMP), via the activity of adenylate cyclases ( $A D C Y$ family) [61]. NAD also provides ADP-ribose and poly-ADP-ribose for post translational modifications of proteins via activity of ADP-ribosyl transferases (ART family) and ADP ribose polymerases (PARP family) [62, 63]. cAMP and protein (poly)ADP-ribosylation are important mediators of cell signaling and protein expression [64]. Niacin is synthesized from tryptophan, but in small quantities relative to a healthy dietary intake [65]. Deficiency, known as pellagra, is marked by dermatitis and severe gastrointestinal/ neurological pathophysiologies which are fatal if untreated [66]. No proteomic studies on systemic intake of vitamin $B_{3}$ were found at the time of writing this review.

\section{Vitamin $B_{5}$}

Pantothenic acid (vitamin $\mathrm{B}_{5}$ ) is composed of a molecule of pantoic acid bound to $\beta$-alanine (Fig. 2) [67]. Its primary metabolic function is as an acyl-carrier [68]. Pantothenic acid is a substrate in the first reaction of coenzyme A $(\mathrm{CoA})$ biosynthesis catalyzed by pantothenate kinases (PANK1, PANK2, PANK3, PANK4) [69]. CoA is a substrate for enzymes catalyzing the oxidative decarboxylation of ketoacids including the pyruvate dehydrogenase complex (PDHA, PDHB, PDHX, DLAT, DLD), the oxoglutarate dehydrogenase complex (OGDH, DLST, $D L D)$, and the branched chain keto acid dehydrogenase complex (BCKDHA, DBT, DLD) [70-72]. Acyl species are activated by conjugation with $\mathrm{CoA}$ and are substrates in or products of glycolysis, the TCA cycle, fatty-acid synthesis/ $\beta$-oxidation, cholesterol synthesis, ketogenesis, branched-chain amino acid catabolism, and protein acetylation/O-GlcNAcylation [73]. Finally, 4'-phosphopanthetheine (product of PANK proteins' activities) is a cofactor of the acyl carrier protein domain of fatty acid synthase $(F A S N)$ [74]. Vitamin $\mathrm{B}_{5}$ deficiency is rare and usually accompanied by that of other nutrients [75]. Burning of the feet and numbness in the toes is a characteristic manifestation along with variety of other symptoms [76]. No proteomic studies on systemic intake of vitamin $B_{5}$ were found at the time of writing this review.

\section{Vitamin $\mathrm{B}_{6}$}

Vitamin $\mathrm{B}_{6}$ has aldehyde, alcohol, and amine forms (Fig. 2); of which the phosphorylated aldehyde form (pyridoxal phosphate) acts as a cofactor to over 100 enzymes [77]. All three forms of vitamin $\mathrm{B}_{6}$ are phosphorylated by pyridoxal kinase $(P D X K)$ [78]. Both the phosphorylated alcohol and amine forms (pyridoxine phosphate and pyridoxamine phosphate) are converted to pyridoxal phosphate by pyridoxine phosphate oxidase (PNPO) [79]. Pyridoxal phosphate is a cofactor for enzymes catalyzing decarboxylase reactions in gamma-aminobutyric acid (GAD1, GAD2) [80] and serotonin/dopamine biosynthesis $(D D C)$ [81]; as well as for enzymes catalyzing transamination reactions (e.g. GOT1, GOT2, GPT, GPT2) [82], cysteine synthesis (CTH) [83], heme synthesis (ALAS1, ALAS2) [84], carnitine synthesis (3-hydroxy-6-N-trimethyllysine aldolase, gene unidentified) [85], niacin synthesis (KYNU) [86], and sphingolipid synthesis (SPTLC1, SPTLC2) [87]. Pyridoxal phosphate is also an important cofactor for enzymes of one-carbon metabolism (SHMT1 and SHMT2) [88] and glycogen catabolism (PYGL and PYGM) [89]. Vitamin $\mathrm{B}_{6}$ deficiency is rare because of its availability in many foods, and pathophysiologies can be diverse [90].

In a triple-TOF-based study of streptozotocin-induced diabetic rat hippocampi, pyridoxamine treatment prevented long-term recognition memory impairment and regulated protein abundances in a number of diverse pathways; notably upregulating half of the proteins involved in ubiquinol biosynthesis [91]. In a 2DGE-MSbased study of mice hippocampi, the abundances of phosphoglycerate mutase (PGAM1) and cannabinoid receptor-interacting protein 1 (CNRIP1) are reported to be elevated/reduced, respectively, upon administration of pyridoxine. Proteomic changes are accompanied by improved novel object recognition [92].

\section{Vitamin $B_{7}$}

Biotin (vitamin $B_{7}$ ) is composed of a fused-ring structure bound to a valeric acid side chain (Fig. 2) [93]. It is transported across the plasma membrane by the sodium-dependent solute carriers SLC5A6 and SLC19A3 [94, 95]. As a cofactor/post-translational modification, biotin covalently binds lysine residues [96]. It is a cofactor for pyruvate carboxylase $(P C)$, acetyl-CoA carboxylase $(A C A C A)$, propionyl-CoA carboxylase (PCCA), and the methylcrotonyl-CoA carboxylase complex (MCCC1, $M C C C 2$ ) [97]. Histones are also biotinylated, regulating gene expression [98]. The post-translational modification occurs via the activity of holocarboxylase synthetase (HLCS) [99].

Biotin deficiency is rare and has wide ranging pathophysiologies. Eating raw egg whites can prevent its absorption (leading to deficiency) because of its affinity for avidin, a chemical in egg whites that is denatured upon cooking. This observation led to the vitamin's eventual discovery [100]. No proteomic studies on systemic intake of vitamin $B_{7}$ were found at the time of writing this review. 


\section{Vitamin $\mathrm{B}_{9}$}

The term folate (vitamin $B_{9}$ ) is inclusive of a group of compounds composed of a pteridine ring linked to paraaminobenzoic acid with a mono- or polyglutamate tail (Fig. 2) [101]. In its reduced form (tetrahydrofolate), a one-carbon unit cross-links (as $\mathrm{CH}$ or $\mathrm{CH}_{2}$ ) amine groups on the ring structure and aminobenzoic acid, or binds the secondary amine (as a formyl group) on the aminobenzoic acid group [102, 103]. This one-carbon unit is utilized in the synthesis of purines and thymidine, conversion of homocysteine to methionine, interconversion of serine and glycine, and catabolism of histidine; reactions collectively termed one-carbon metabolism $[104,105]$. At the cellular level, one-carbon metabolism is tightly regulated by compartmentalization [104, 106, 107] while whole-body folate homeostasis is predominantly maintained by the liver through the enterohepatic cycle [108].

Folate deficiency induces megaloblastic macrocytic anemia and fetal neural tube defects, purportedly via its adverse impact on nucleotide synthesis $[109,110]$. Low intake of folate is also linked to cardiovascular disease $[111,112]$, neurodegenerative disease [113, 114], Alzheimer's disease $[115,116]$ and cancer [117-119].

In an orbitrap-based study of follicle fluid of women undergoing in vitro fertilization, the folate supplemented group is reported to have elevated abundances of apolipoproteins from high density lipoproteins and reduced reactive protein $\mathrm{c}(C R P)$. The study is performed on women who did not become pregnant [120]. In a QTOF-based study of a folate-deficiency-induced intestinal neoplasia mouse model, the combinatorial impacts of folate deficiency and methylene tetrahydrofolate reductase heterozygous deletion $\left(m t h \mathrm{fr}^{+-}\right)$are reported to impact protein abundances spanning diverse cellular functions. However $40 \%$ of samples are discarded as outliers and the simultaneous examination of $m t h \mathrm{fr}^{+/-}$and dietary folate deficiency does not allow proteomic adaptations to be attributed to either in isolation [121]. In a 2DGE-MS-based study of adult rats, aortic calmodulin (CALM1, calcium signaling) protein abundances are positively correlated with folate dose while abundances of triose phosphate isomerase (TPI1, glycolysis), transgelin (TAGLN, cytoskeleton), and glutathione s-transferase alpha 3 (GSTA3, reductive detoxification) respond inversely [122]. In an 2DGE-MS-based study of rat livers, PRDX6 and GPX1 are reported to be elevated while cofilin (CFL1) is reported to be depleted under folate deficiency [123]. Other studies report protein abundance differences due to folate intake in rat urinary exosomes (QQQ-based) [124], human plasma (2DGE-MS) [125], fetal brain tissue from pregnant mice fed ethanol (2DGE-MS) [126], pregnant rat livers (2DGE-MS) [127], fetal rat livers (2DGE-MS) [128], adult rat livers and brains (2DGE-MS) [129], and livers of piglets born to folate deficient mothers (2DGE-MS) [130].

\section{Vitamin $\mathrm{B}_{12}$}

Cobalamin (vitamin $B_{12}$ ) encompasses a group of molecules with four linked pyrrole ring derivatives (forming a corrin ring) and a cobalt atom bound at the center of the corrin ring. The cobalt atom also binds a 5,6-dimethylbenzimidazole nucleotide and a functional group (Fig. 2) [131]. The identity of the functional group distinguishes the vitamin $B_{12}$ compounds as cyanocobalamin, hydroxycobalamin, hydrocobalamin, nitrocobalamin, 5'-deoxyadenosylcobalamin (also called adenosylcobalamin), and methyl cobalamin [132, 133]. Methylcobalamin serves as a coenzyme in the conversion of homocysteine to methionine by methionine synthase (MTR) in the cytosol [134] and adenosylcobalamin is required for conversion of L-methylmalonyl-CoA to succinyl-CoA by methylmalonyl-CoA mutase (MUT) in mitochondria [135].

Vitamin $B_{12}$ deficiency is closely related to folate deficiency and can lead to megaloblastic anemia by impairment in the activity of methionine synthase (MTR) [109]: 5-methyl tetrahydrofolate cannot be converted to one-carbon donors required for purine and thymidine synthesis without vitamin $B_{12}$ as a cofactor, thus interfering with DNA synthesis and erythrocyte production [136]. Vitamin $B_{12}$ deficiency is also linked to neurological disorders independent of anemia [137].

Ruoppolo and colleagues performed a 2DGE-MSbased study of lymphocytes isolated from methylmalonic acidemia with homocystinuria, cobalamin deficiency type $\mathrm{C}$ (MMACHC) patients (an inborn error in metabolism marked by inactivity of the $M M A C H C$ gene product) receiving a standard treatment of hydroxycobalamin, betaine, folate, and carnitine. Protein products of $M E 2$, GLUD1, and GPD2, genes involved in anaplerosis and redox equivalent shuttling, are up-regulated while variant 2 of protein pyruvate kinase muscle isozyme (PKM) and lactate dehydrogenase $\mathrm{B}(L D H B)$ are down-regulated relative to lymphocytes isolated from healthy control donors [138]. In a 2DGE-based study of adult rat cerebral spinal fluid, protein abundance shifts are reported to peak after several months on a cobalamin deficient diet (modest shifts) or after a total gastrectomy (more severe shifts), and return to near control values at later time points [139]. In a 2DGE-MS-based study, glutathione stransferase P (GSTP1) abundances are diminished and glutathione peroxidase 1 (GPX1) abundances are elevated in rat pup kidneys under maternal vitamin $B_{12}$ deficient and maternal folate deficient conditions [140]; suggesting maternal dietary intake of these vitamins impacts offspring kidney redox homeostasis mechanisms. 
In a similar 2DGE-MS-based study of maternal vitamin $B_{12}$ deficiency, the same group reports that several dozen rat kidney pup proteins revert to control levels upon administration of vitamin $\mathrm{B}_{12}$ at birth. Additionally, diminished abundance of beta-oxidation proteins in kidneys of pups born to vitamin $B_{12}$ deficient mothers is accompanied by elevated PPARA [141], a positive regulator of fatty acid oxidation, suggesting attempted compensation at the cellular level.

\section{Vitamin C}

Vitamin C (ascorbic acid) is absorbed at the brushborder and distributed to cells throughout the body by the sodium-dependent plasma membrane solute carriers SLC23A1 and SLC23A2 [142]. The oxidized form of vitamin $\mathrm{C}$ (dehydroascorbate) is also transported via plasma membrane glucose transporters $S L C 2 A 1, S L C 2 A 3$, and SLC2A4 (also known as GLUT1, GLUT3, and GLUT4) [143] and reduced intracellularly to ascorbic acid by glutathione [144] and the activity of thioredoxin reductases (TXNRD1, TXNRD2, or TXNRD3) [145].

Vitamin $C$ is a cofactor in the function of prolyl and lysyl hydroxylases, which consume oxygen and alphaketoglutarate to form the hydroxylated amino acid residue and succinate [146]. The $\mathrm{Fe}^{2+}$ of these enzymes is restored from $\mathrm{Fe}^{3+}$ by oxidation of vitamin $C$ [147]. In the presence of oxygen, prolyl hydroxylases (EGLN1, EGLN2, EGLN3; also known as $P H D 2, P H D 1, P H D 3$ respectively) hydroxylate the HIF1A protein; providing a necessary signal for its degradation and preventing a hypoxic response at the cellular level [148]. Prolyl and lysyl hydroxylase activities are also necessary for post-translational modifications to form functional collagen [149]. Lysyl hydroxylases include PLOD1, PLOD2, and PLOD3 [150]. Vitamin C serves a nearly identical function in reducing $\mathrm{Fe}^{3+}$ as a cofactor for trimethyllysine dioxygenase $(T M L H)$, which catalyzes the first reaction in carnitine biosynthesis [151]. Carnitine is essential for fatty acid catabolism in the mitochondria as only fatty acyl carnitines formed via the activity of carnitine palmitoyl transferases $C P T 1 A, C P T 1 B$, and $C P T 1 C$ cross the inner mitochondrial membrane through the solute carrier SLC25A20 [152]. Vitamin C similarly serves as a cofactor for tyrosine hydroxylase $(T H)$, which catalyzes the first reaction in catecholamine (e.g. dopamine, epinephrine, and norepinephrine) synthesis [153]. Additionally, vitamin $\mathrm{C}$ serves and as a general antioxidant [154]. Vitamin C deficiency leads to the condition known as scurvy with symptoms largely attributed to malformed connective tissue due to improperly folded collagen [155].

In a orbitrap-based study on a pig model of hemorrhagic shock, vitamin $\mathrm{C}$ administration is reported to impact plasma protein abundances in the complement pathway and those in poly-trauma related processes; including the stabilization of ADAMTS13 abundance, an important regulator of clot formation [156]. An orbitrap-based study of endoplasmic reticulum enriched fractions of livers in Werner syndrome mouse models identifies around a dozen proteins whose abundances are impacted by administration of vitamin C [157]. A QTOF-based study of zebrafish reports upregulation of glutamate dehydrogenase (GLUD1) and downregulation of pyruvate kinase muscle isozyme (PKM) upon administration of vitamin $C$ in a vitamin E deficient background [158]. In a QQQbased study of human plasma, ascorbic acid concentration is reported to be inversely related to vitamin $\mathrm{D}$ binding protein $(G C)$ abundance [159]. 2DGE-MS-based studies identify protein abundance regulations in mouse models of sarcoma metastases in the liver [160] and tumor nodules of adenocarcinoma due to administration of vitamin C [161]. Another 2DGE-MS-based study reports polypeptide abundance shifts in hemodialysis patient plasma upon vitamin C supplementation [162].

\section{Vitamin D}

Vitamins $D_{2}$ and $D_{3}$ are respectively distinguished by their ergosterol and cholesterol backbones [163]. Though only vitamin $D_{3}$ is synthesized in animals, both can be converted to active forms. Exposure of 7-dehydrocholesterol (an intermediate in cholesterol synthesis) to ultra-violet radiation in the skin and subsequent isomerization produces cholecalciferol (vitamin $D_{3}$, Fig. 1) [164]. Whether 7dehydrocholesterol is derived from cholesterol via activity of 7-dehydrocholesterol reductase (DHCR7) or synthesized de novo in the skin is disputed [165]. 7-dehydrocholesterol is successively hydroxylated by activity of cytochrome $\mathrm{p} 450$ enzymes (e.g. CYP2R1 and CYP27B1) in the liver and kidney to its active $1,25-(\mathrm{OH})_{2}$ cholecalciferol $\left[1,25(\mathrm{OH})_{2} \mathrm{D}_{3}\right]$ form [166]. Transport of vitamin D and its metabolites occurs bound to vitamin D binding protein $(G C)$ [167]. Ergocalciferol is the vitamin $\mathrm{D}_{2}$ equivalent of cholecalciferol and is activated analogously [168].

$1,25(\mathrm{OH})_{2} \mathrm{D}_{3}$ influences cellular function via nuclear receptor-dependent and nuclear receptor-independent mechanisms. The former involves $1,25(\mathrm{OH})_{2} \mathrm{D}_{3}$-bound vitamin $\mathrm{D}$ receptor $(V D R)$ forming a heterodimer complex with a retinoid $\mathrm{X}$ receptor (RXRA, RXRB, RXRG) and subsequently binding vitamin $\mathrm{D}$ response elements regulating transcription of genes largely involved modulating calcium and phosphorous transport [169] and maintaining homeostasis by regulating their absorption in the kidneys, intestines, and bones [170, 171]. The rapid-onset extracellular impacts (nuclear receptorindependent) of $1,25(\mathrm{OH})_{2} \mathrm{D}_{3}$ are mediated by a membraneassociated rapid response steroid binding protein, identified 
as PDIA3 [172], and diversely impact cell growth, survival, and immune response [173].

Deficiency in vitamin D impairs bone mineralization causing rickets in infants/children and osteomalacia in adults [174]. Vitamin D deficiency is also linked to cardiovascular diseases [175, 176], cancer [177, 178], neurological impairments $[179,180]$ and autoimmune diseases [181, 182]; though underlying mechanisms are not completely understood.

In an orbitrap-based study of mouse fetal and postnatal lung tissue, maternal vitamin D deficiency is reflected in total proteome adaptations which are unexpectedly strongest at postnatal day 7 opposed to fetal time points. Impacted proteins include several associated with lung development [183]. An orbitrap-based study of a mouse brain tissue model of remyelination in multiple sclerosis reports calcium binding protein abundances to be upregulated upon treatment with $1,25(\mathrm{OH})_{2} \mathrm{D}_{3}$, consistent with the vitamin's regulatory role over calcium absorption [184]. In an orbitrap-based study of serum from overweight adults, vitamin D deficiency is reported to differentially affect abundances of proteins related to blood coagulation in males and females. However, abundances of these proteins are likely impacted by the production of serum from whole blood. The authors report quantifying 1,841 proteins (Table 1); an impressive analytical depth for serum [188]. In a 2DGE-based study, vitamin $\mathrm{D}$ deficient children are reported to have diminished serum abundances of adiponectin (ADIPOQ) [189]. In a separate 2DGE-based study, the same group reports fetuin-b (FETUB) to be elevated in the plasma of obese vitamin D deficient children compared with their vitamin D sufficient counterparts [190]. However the authors do not directly identify FETUB and rely on comparison of their findings to those of another study [191]. Two 2DGE-MS-based studies, of rat left ventricular and aortic tissue, identify proteins whose abundances respond upon inducing arterial calcification or atherosclerosis by co-administration of vitamin $\mathrm{D}_{3}$ with nicotine or a high cholesterol diet respectively [192, 193]. Two studies (2DGE-MS and 2DGE-based respectively) examine the impacts of vitamin $\mathrm{D}$ deficiency on the rat brain proteome. The former reports the progeny of vitamin $\mathrm{D}$ deficient mothers to have diminished abundances of ATP synthase $\beta(A T P B)$ and enolase 2 (ENO2) in both the cortex and hippocampus, and diminished calmodulin (CALM1) in the hippocampus amongst a variety of other regulated proteins [194]. The latter finds low vitamin D diets to be accompanied by diminished cortical abundances of three glycolytic enzymes: triose phosphate isomerase (TPI1); phosphofructokinase, platelet (PFKP); and pyruvate kinase, muscle $(P K M)$ [195].

Table 1 Summary of key findings

\begin{tabular}{|c|c|}
\hline Vitamin & Key Findings \\
\hline Vitamin A & $\begin{array}{l}\text { Creation of a model of craniofacial disorders induced by prenatal retinoic acid exposure is reported to impact protein abundances } \\
\text { whose functions are associated with neural crest processes [30]. Plasma carotenoids abundances are reported to be associated with } \\
\text { plasma proteins of diverse functions in Nepalese children, potentiating development of inexpensive assays to predict carotenoids } \\
\text { deficiency [32]. }\end{array}$ \\
\hline Vitamin $B_{1}$ & $\begin{array}{l}\text { Treatment with thiamine is presented as a potential strategy to improve kidney function in type } 2 \text { diabetic patients [41]. Thiamine } \\
\text { deficiency is reported to impact cognition in rats [42]. }\end{array}$ \\
\hline Vitamin $B_{2}$ & $\begin{array}{l}\text { Dietary and maternal dietary riboflavin are reported to impact the machineries of lipid metabolism and fetal lipid metabolism in ducks } \\
{[51,52] \text {. }}\end{array}$ \\
\hline Vitamin $B_{6}$ & $\begin{array}{l}\text { A study of a rat model of diabetes reports treatment with pyridoxamine to impact abundances of proteins involved in synaptic plasticity } \\
\text { in hippocampi and to have protective effects on long-term memory [91]. }\end{array}$ \\
\hline Vitamin $B_{9}$ & $\begin{array}{l}\text { Folate supplementation in women undergoing in vitro fertilization is reported to increase abundances of apolipoproteins of } \\
\text { high-density lipoproteins in monofollicular fluid [120]. }\end{array}$ \\
\hline Vitamin $B_{12}$ & $\begin{array}{l}\text { Maternal cobalamin deficiency is reported to impact abundances of proteins related to lipid metabolism in the offspring kidneys of } \\
\text { rats [141]. }\end{array}$ \\
\hline Vitamin C & $\begin{array}{l}\text { Treatment with ascorbic acid is reported to impact plasma abundances of proteins involved in the complement pathway and regulation } \\
\text { of clot formation in a pig model of hemorrhagic shock [156]. }\end{array}$ \\
\hline Vitamin D & $\begin{array}{l}\text { Maternal vitamin D deficiency is reported to impact abundances of proteins involved in mouse neonatal lung development during } \\
\text { alveolar development stages without affecting gross lung structure [183]. Treatment with } 1,25(\mathrm{OH})_{2} \mathrm{D}_{3} \text { is reported to increase } \\
\text { abundances of proteins involved in calcium homeostasis in a mouse brain model of remyelination [184]. }\end{array}$ \\
\hline Vitamin E & $\begin{array}{l}\text { A quantitative model based on plasma protein abundances is reported to predict plasma a-tocopherol status, potentiating the } \\
\text { development of an inexpensive assay to detect a-tocopherol deficiency [185]. A study of a mouse model of Alzheimer's disease reports } \\
\text { treatment with the tocotrienol-rich fraction of palm oil reduces the abundance of amyloid beta A4 protein, the primary component } \\
\text { of amyloid plaques, in hippocampi [186]. }\end{array}$ \\
\hline Vitamin K & $\begin{array}{l}\text { A quantitative model based on five plasma protein abundances is reported to predict vitamin } \mathrm{K} \text { deficiency with moderate } \\
\text { accuracy [187]. }\end{array}$ \\
\hline
\end{tabular}




\section{Vitamin E}

Members of the vitamin E class of molecules all contain fused phenyl and chromanol rings linked to a 16-carbon side-chain [196]. Methyl group placement on the phenyl ring dictates $\alpha, \beta, \gamma$, and $\delta$ designation while side-chain saturation state distinguishes tocopherols from tocotrienols (Fig. 1). Furthermore, all forms of vitamin $\mathrm{E}$ have three chiral centers resulting in 8 stereoisomers [197]. RRR $\alpha$-tocopherol is the most biologically active form, likely due to specificity of $\alpha$-tocopherol transfer protein (TTPA) whose binding is necessary for packaging and transport to tissues from the liver [198]. $\alpha$-tocopherol primarily localizes to membranes (i.e. plasma, endoplasmic reticulum, and mitochondrial) and functions as an antioxidant for unsaturated, lipid-bound fatty acids [196]. Atocopherol also has non-antioxidant signal-transduction functions impacting a broad range of cellular activities [199].

Vitamin E deficiency is rare due to the availability of the vitamin in the diet [200], though it may be caused by a genetic defect in $\alpha$-tocopherol transfer protein (TTPA) and diseases associated with fat malabsorption [201, 202]. Severe vitamin E deficiency can result in hemolytic anemia, neurological disorders, and ataxia [201, 203-205].

An orbitrap-based study of plasma from undernourished Nepalese children reports plasma $\alpha$-tocopherol concentration to be positively correlated with abundances of a number of apolipoproteins (APOs) and negatively correlated with the muscle isozyme of the protein pyruvate kinase $(P K M)$. Authors establish a linear model based on a handful of protein quantities that accounts for most variance in $\alpha$-tocopherol plasma concentration and suggest an inexpensive, portable, antibody-based methodology can be used to assay plasma $\alpha$-tocopherol abundance in low-income countries [185]. An orbitrapbased study of hippocampi, medial prefrontal cortices, and striata tissue in a mouse model of Alzheimer's disease reports administration of a tocotrienol-rich fraction of palm oil down-regulates hippocampi expression of the amyloid beta $\mathrm{A} 4$ protein $(A P P)$. Amyloid beta $\mathrm{A} 4$ is the principle component of amyloid plaques characteristic of Alzheimer's disease [186]. In a QTOF-based study of rabbit aortae, vitamin $\mathrm{E}$ supplementation is reported to impact protein abundances including the apolipoprotein, $A P O A 1$, and several related to oxidation/reduction processes [206]. 2DGE-MS-based studies also report vitamin $\mathrm{E}$ supplementation to impact apolipoprotein abundances in human plasma [207, 208]. In a 2DGEbased study of high-density reared rainbow trout livers, vitamin $\mathrm{E}$ supplementation is reported to regulate the abundances of a handful of heat shock and metabolic proteins [209]. Finally, a 2DGE-MS-based study reports vitamin $\mathrm{E}$ supplementation to regulate a number of plasma protein abundance in patients harboring prostate tumors [210].

\section{Vitamin K}

Vitamin K compounds all share a common fused benzyl and methyl-naphthoquinone ring moiety (Fig. 1). Naturally occurring vitamin K compounds include phylloquinone and menaquinones [211]. Vitamin $\mathrm{K}$ is a necessary cofactor of gamma-glutamyl carboxylase (GGCX), an enzyme which catalyzes the carboxylation of glutamate protein residues to carboxyglutamate residues [212]. This post-translational modification is necessary for the function of proteins of the coagulation cascade $(F 2, F 7, F 9, F 10)$, proteins inhibiting coagulation (PROC, PROS1, PROZ), and those associated with connective tissue matrix formation (BGLAP, MGP) [213]. Newborn infants are among the most at-risk for vitamin $K$ deficiency because they do not have adequate stores and milk is not a sufficient source. Thus a phylloquinone injection shortly after birth is recommended [214]. Elevated risk of hemorrhage is associate with vitamin K deficiency [215].

In an orbitrap-based study of plasma from Nepalese children, authors create a model based on five protein abundances which can predict vitamin K deficiency with moderate accuracy. Vitamin $\mathrm{K}$ status is based on a surrogate measurement of an abundance of an abnormal form of prothrombin [187].

\section{Conclusions}

Proteomic studies have established dietary vitamin status as a regulator of tissue protein abundances. The regulatory feedback between vitamin status and protein expression is highlighted by findings where the abundances of proteins directly related to the vitamin are impacted by systemic intake of that vitamin, including: abundances of proteins related to craniofacial development and neural crest processes are impacted in an established maternal retinoic acid toxicity-driven model of craniofacial birth defects [30], deficiency in their riboflavin cofactor is accompanied by reduced abundances of acyl-coenzyme A dehydrogenases and accumulation of the enzymes' substrates [51], treatment with the active form of vitamin $\mathrm{D}$ is accompanied by increased expression of calcium binding proteins [184], and vitamin E supplementation impacts proteins related to redox processes [206] (Table 1). However, the literature in this field is sparse and, in all likelihood, the vast majority of vitamin-status to protein abundance relationships are undescribed; especially considering the void in the literature for several vitamins. Moreover, the field has not advanced to explore the mechanisms of these regulations, their biological impacts, or their potential to shape clinical interventions.

Modern proteomic platforms are ever increasing achievable depth, where analysis of whole mammalian tissue [216-220] or plasma [221, 222] routinely results 
Table 2 Summary of Technical Depth of Orbitrap-, QTOF-, and Triple-TOF-based Studies. A protein only needs to be identified in one sample to contribute to the total number of unique proteins (indicated as "total" below), thus the total is typically larger in studies with greater sample numbers. An iTRAQ or TMT set is a pool of samples that are run on the LC-MS/MS concurrently. Because the samples in a set are all analyzed simultaneously, a set's contribution to the total number of unique proteins is similar to that of a single sample

\begin{tabular}{|c|c|c|c|c|c|}
\hline Study & Year & Platform & Tissue & \# Proteins Identified & \# Samples \\
\hline [30] & 2018 & Orbitrap & mouse embryo heads & $\begin{array}{l}\text { group 1: } 313 \text { total } \\
\text { group 2: } 372 \text { total }\end{array}$ & 2 groups \\
\hline [31] & 2018 & Triple-TOF & gerbil plasma & 109 total & 30 \\
\hline$[32,185,187]$ & 2015 & Orbitrap & human plasma & $\begin{array}{l}4,705 \text { total } \\
589 / \text { set }\end{array}$ & 72 iTRAQ sets \\
\hline [42] & 2018 & QTOF & rat thalami & 1,440 total & $6 \times 3$ tech. reps. \\
\hline [51] & 2017 & QTOF & duck livers & 1,749 total & 3 iTRAQ sets \\
\hline [52] & 2019 & QTOF & fetal duck livers & 3,801 total & 1 iTRAQ set \\
\hline [91] & 2019 & Triple-TOF & rat hippocampi & 4,807 total & 2 iTRAQ sets \\
\hline [120] & 2015 & Orbitrap & human follicular fluid & 227 total & 1 TMT set \\
\hline [121] & 2014 & QTOF & mouse intestine & 2,039 total & 10 \\
\hline [156] & 2019 & Orbitrap & pig plasma & 534 total & 45 \\
\hline [157] & 2018 & Orbitrap & mouse liver fraction & 4,058 total & 9 \\
\hline [158] & 2014 & QTOF & zebrafish & 2,956 total & 19 \\
\hline [183] & 2016 & Orbitrap & mouse lung & $\begin{array}{l}1,160 \text { total, } \\
240 \text { common to all }\end{array}$ & 34 \\
\hline [184] & 2018 & Orbitrap & mouse brain & 5,062 total & 1 TMT set \\
\hline [188] & 2016 & Orbitrap & human serum & 1,841 total & 1 iTRAQ set \\
\hline [186] & 2019 & Orbitrap & mouse brain tissues & $\begin{array}{l}\text { group 1: } 5,847 \text { total } \\
\text { group 2: } 6,047 \text { total }\end{array}$ & 2 groups of 6 \\
\hline [206] & 2013 & QTOF & rabbit aortae & 100 total & $24 \times 3$ tech. reps. \\
\hline
\end{tabular}

in 10,000 or 1,500 unique proteins quantified per sample respectively. Furthermore, advances continue in capacity to detect post-translational modifications [223, 224], determine compartmental localization [225], and apply findings in clinical settings [226]. In a golden age of proteomic technological advances, studies of vitamin intake have not kept pace. Of those using orbitrap, QTOF, or triple-TOF systems, many fall short of the cutting edge of analytical depth (Table 2); whereas most studies have relied on antiquated 2DGE-MS platforms. Outdated platforms rendering fewer quantified proteins are likely contributors to clustering [227] or enrichment analysis techniques [228-234] not being widely employed. These high-throughput methods of data analysis provide systems-level stratification of proteome-wide adaptations and can guide targeted inquiries. As the study of precision nutrition advances in an era of big data, fundamental questions of nutrient-protein interactions will be at the forefront of understanding molecular mechanisms of nutrient and substrate processing. Where the sparsity of the literature leaves fundamental questions unanswered, opportunity for rapid advancement lies with application of cutting-edge technologies in well-designed and executed studies.

\section{Supplementary information}

Supplementary information accompanies this paper at https://doi.org/10. 1186/s12986-020-00491-7.

Additional file 1: Tables S1 - S13. Ensyme, enzyme complexes, or enzyme families requiring vitamins as a cofactor or substrate.

\section{Abbreviations}

Roman numerals I-IV: Electron transport chain complexes I-IV; 2DGE: Twodimensional gel electrophoresis; 2DGE-MS: 2DGE - mass spectrometry; 3PG: 3-phosphoglycerate; 6PG: 6-phosphogluconate; 6PGL: 6phosphogluconolactone; AcAc: Acetoacetate; AcCoA: Acetyl-CoA: ADP: Adenosine diphosphate; aKG: Alpha ketoglutarate; Ala: Alanine; Asp: Aspartate; ATP: Adenosine triphosphate; CoA: Coenzyme A; Cit: Citrate; CTP: Cytidine triphosphate; DHO: Dihydroorotate; DNA: Deoxyribonucleic acid; dTMP: Deoxythymidine monophosphate; dUDP: Deoxyuridine diphosphate; dUMP: Deoxyuridine monophosphate; F6P: Fructose 6phosphate; Fum: Fumarate; G3P: Glyceraldehyde 3-phosphate; G6P: Glucose 6-phosphate; Glc: Glucose; GlcN: Glucosamine; GlcNAc: N-acetylglucosamine; Gln: Glutamine; Glu: Glutamate; Gly: Glycine; Hcy: Homocysteine;

HIF1a: Hypoxia inducible factor 1 subunit alpha; HMGCoA: 3-hydroxy-3methylglutaryl-CoA; IC: Isocitrate; Ile: Isoleucine; Leu: Leucine; Mal: Malate; mDNA: Methylated DNA; Met: Methionine; MMCoA: Methylmalonyl-CoA; Oac: Oxaloacetate; PEP: Phosphoenolpyruvate; PPCoA: Propionyl-CoA; Pyr: Pyruvate; QTOF: Quadrupole time-of-flight; QQQ: Triple-quadrupole; R5P: Ribose 5-phosphate; reps.: Replicates; Ru5P: Ribulose 5-phosphate; SAH: S-adenosylhomocysteine; SAM: S-adenosylmethionine; Ser: Serine; Suc: Succinate; SucCoA: Succinyl-CoA; tech.: Technical; THF: Tetrahydrofolate; Thr: Threonine; UDP: Uridine diphosphate; UTP: Uridine triphosphate; UQ: Ubiquinone; Val: Valine; X5P: Xylulose 5-phosphate 


\section{Acknowledgements}

The authors wish to acknowledge invaluable resources for fundamental information presented in this work [235-237].

\section{Authors' contributions}

$\mathrm{HJ}$ and NMV contributed to searching the literature, writing, and editing. The author(s) read and approved the final manuscript.

\section{Funding}

Not Applicable

\section{Availability of data and materials}

All data presented herein is available from the referenced sources.

\section{Ethics approval and consent to participate}

Not applicable

\section{Consent for publication}

Not applicable

\section{Competing interests}

The authors declare that they have no competing interests.

\section{Received: 31 January 2020 Accepted: 7 August 2020}

Published online: 26 August 2020

\section{References}

1. Metallo CM, Vander Heiden MG. Understanding metabolic regulation and its influence on cell physiology. Mol Cell. 2013;49(3):388-98.

2. Dervartanian DV, Veeger C. Studies on succinate dehydrogenase. II. On the nature of the reaction of competitive inhibitors and substrates with succinate dehydrogenase. Biochim Biophys Acta. 1965;105(3):424-36.

3. Underwood AH, Newsholme EA. Control of glycolysis and gluconeogenesis in rat kidney cortex slices. Biochem J. 1967;104(1):300-5.

4. Nguyen T, Nioi P, Pickett CB. The Nrf2-antioxidant response element signaling pathway and its activation by oxidative stress. J Biol Chem. 2009; 284(20):13291-5.

5. Kopperschläger $\mathrm{G}$, Kirchberger J. Methods for the separation of lactate dehydrogenases and clinical significance of the enzyme. J Chromatogr B Biomed Appl. 1996;684(1-2):25-49.

6. Patel MS, et al. The pyruvate dehydrogenase complexes: structure-based function and regulation. J Biol Chem. 2014;289(24):16615-23.

7. Metallo $\mathrm{CM}$, et al. Reductive glutamine metabolism by IDH1 mediates lipogenesis under hypoxia. Nature. 2011;481(7381):380-4.

8. Efeyan A, Comb WC, Sabatini DM. Nutrient-sensing mechanisms and pathways. Nature. 2015;517(7534):302-10.

9. Kandel ES, Hay N. The regulation and activities of the multifunctional serine/ threonine kinase Akt/PKB. Exp Cell Res. 1999;253(1):210-29.

10. Lefebvre $P$, et al. Transcriptional activities of retinoic acid receptors. Vitam Horm. 2005;70:199-264.

11. Kojo S. Vitamin C: basic metabolism and its function as an index of oxidative stress. Curr Med Chem. 2004;11(8):1041-64.

12. Minor EA, et al. Ascorbate induces ten-eleven translocation (Tet) methylcytosine dioxygenase-mediated generation of 5hydroxymethylcytosine. J Biol Chem. 2013;288(19):13669-74.

13. Carlberg C, Seuter S. A genomic perspective on vitamin D signaling. Anticancer Res. 2009;29(9):3485-93.

14. Pike JW, Christakos S. Biology and Mechanisms of Action of the Vitamin D Hormone. Endocrinol Metab Clin North Am. 2017;46(4):815-43.

15. Kamanna VS, Kashyap ML. Mechanism of action of niacin on lipoprotein metabolism. Curr Atheroscler Rep. 2000;2(1):36-46.

16. Chapman-Smith A, Cronan JE Jr. The enzymatic biotinylation of proteins: a post-translational modification of exceptional specificity. Trends Biochem Sci. 1999;24(9):359-63.

17. Rochat, B., Quantitative and Qualitative LC-High-Resolution MS: The Technological and Biological Reasons for a Shift of Paradigm, in Recent Advances in Analytical Chemistry. 2018, IntechOpen.

18. Bromirski M. First choice in high resolution mass spectrometry with Orbitrap mass analyzer technology for screening, confirmative and quantitative analyses. Thermo Scientific. White Paper 65146. 2018.
19. Alelyunas YW, et al. Effect of MS Scan Speed on UPLC Peak Separation and Metabolite Identification: Time-of-Flight HRMS vs. Orbitrap: Waters Corporation; 2013

20. Sporn MB, et al. Relationships between structure and activity of retinoids. Nature. 1976;263(5573):110-3.

21. von Lintig J. Provitamin A metabolism and functions in mammalian biology. Am J Clin Nutr. 2012;96(5):1234s-44s.

22. Amengual J, et al. Two carotenoid oxygenases contribute to mammalian provitamin A metabolism. J Biol Chem. 2013;288(47):34081-96.

23. Bownds D. Site of attachment of retinal in rhodopsin. Nature. 1967; 216(5121):1178-81.

24. Jacobson SG, et al. Night blindness in Sorsby's fundus dystrophy reversed by vitamin A. Nat Genet. 1995;11(1):27-32.

25. Petkovich M. Regulation of gene expression by vitamin $A$ : the role of nuclear retinoic acid receptors. Annu Rev Nutr. 1992:12:443-71.

26. Szanto A, et al. Retinoid X receptors: X-ploring their (patho) physiological functions. Cell Death Differ. 2004;11(Suppl 2):S126-43.

27. Herr FM, Ong DE. Differential interaction of lecithin-retinol acyltransferase with cellular retinol binding proteins. Biochemistry. 1992:31(29):6748-55.

28. Kim Cl, Leo MA, Lieber CS. Retinol forms retinoic acid via retinal. Arch Biochem Biophys. 1992;294(2):388-93.

29. Wiseman EM, Bar-El Dadon S, Reifen R. The vicious cycle of vitamin a deficiency: A review. Crit Rev Food Sci Nutr. 2017:57(17):3703-14.

30. Berenguer $M$, et al. Prenatal retinoic acid exposure reveals candidate genes for craniofacial disorders. Sci Rep. 2018;8(1):17492.

31. Bohn T, et al. Proteomic responses of carotenoid and retinol administration to Mongolian gerbils. Food Funct. 2018;9(7):3835-44.

32. Eroglu A, et al. Plasma proteins associated with circulating carotenoids in Nepalese school-aged children. Arch Biochem Biophys. 2018;646:153-60.

33. Zhang $M$, et al. Proteome alterations of cortex and hippocampus tissues in mice subjected to vitamin A depletion. J Nutr Biochem. 2011; 22(11):1003-8.

34. Campos CF, et al. Proteomic analysis reveals changes in energy metabolism of skeletal muscle in beef cattle supplemented with vitamin A. J Sci Food Agric. 2020;100(8):3536-43.

35. Brown G. Defects of thiamine transport and metabolism. J Inherit Metab Dis. 2014;37(4):577-85

36. Ganapathy V, Smith SB, Prasad PD. SLC19: the folate/thiamine transporter family. Pflugers Arch. 2004:447(5):641-6.

37. Jordan F. Current mechanistic understanding of thiamin diphosphatedependent enzymatic reactions. Nat Prod Rep. 2003;20(2):184-201.

38. Kochetov GA, Solovjeva ON. Structure and functioning mechanism of transketolase. Biochim Biophys Acta. 2014;1844(9):1608-18.

39. Bettendorff $L$, Wins $P$, Schoffeniels $E$. Regulation of ion uptake in membrane vesicles from rat brain by thiamine compounds. Biochem Biophys Res Commun. 1990;171(3):1137-44

40. Lonsdale D. Thiamin. Adv Food Nutr Res. 2018:83:1-56.

41. Riaz S, Skinner V, Srai SK. Effect of high dose thiamine on the levels of urinary protein biomarkers in diabetes mellitus type 2. J Pharm Biomed Anal. 2011;54(4):817-25.

42. Nunes PT, et al. Thalamic Proteome Changes and Behavioral Impairments in Thiamine-deficient Rats. Neuroscience. 2018;385:181-97.

43. Massey $\vee$. The chemical and biological versatility of riboflavin. Biochem Soc Trans. 2000;28(4):283-96

44. Barile $\mathrm{M}$, et al. Riboflavin transport and metabolism in humans. J Inherit Metab Dis. 2016;39(4):545-57.

45. Lienhart WD, Gudipati V, Macheroux P. The human flavoproteome. Arch Biochem Biophys. 2013;535(2):150-62.

46. Chan J, et al. Low dietary choline and low dietary riboflavin during pregnancy influence reproductive outcomes and heart development in mice. Am J Clin Nutr. 2010;91(4):1035-43.

47. Yates CA, Evans GS, Powers HJ. Riboflavin deficiency: early effects on post-weaning development of the duodenum in rats. Br J Nutr. 2001; 86(5):593-9.

48. Powers HJ, et al. Riboflavin deficiency in the rat: effects on iron utilization and loss. Br J Nutr. 1991:65(3):487-96.

49. Bian X, et al. Riboflavin deficiency affects lipid metabolism partly by reducing apolipoprotein B100 synthesis in rats. J Nutr Biochem. 2019;70:75-81.

50. Olpin SE, Bates CJ. Lipid metabolism in riboflavin-deficient rats. 1. Effect of dietary lipids on riboflavin status and fatty acid profiles. Br J Nutr. 1982:47(3): 577-96. 
51. Tang J, et al. Severe riboflavin deficiency induces alterations in the hepatic proteome of starter Pekin ducks. Br J Nutr. 2017;118(9):641-50.

52. Tang J, et al. Maternal diet deficient in riboflavin induces embryonic death associated with alterations in the hepatic proteome of duck embryos. Nutr Metab (Lond). 2019;16:19.

53. Cantó C, Menzies K, Auwerx J. NAD(+) Metabolism and the Control of Energy Homeostasis: A Balancing Act between Mitochondria and the Nucleus. Cell Metab. 2015;22(1):31-53.

54. Magni G, et al. Enzymology of NAD+ homeostasis in man. Cell Mol Life Sci. 2004;61(1):19-34.

55. Meyer-Ficca M, Kirkland JB. Niacin. Adv Nutr. 2016;7(3):556-8.

56. Njus $D$, et al. Mechanism of ascorbic acid regeneration mediated by cytochrome b561. Ann N Y Acad Sci. 1987;493:108-19.

57. Vogel $\mathrm{R}$, et al. The regeneration of reduced glutathione in rat forebrain mitochondria identifies metabolic pathways providing the NADPH required. Neurosci Lett. 1999;275(2):97-100.

58. Arnér ES, Holmgren A. Physiological functions of thioredoxin and thioredoxin reductase. Eur J Biochem. 2000;267(20):6102-9.

59. Lerner $F$, et al. Structural and functional characterization of human NAD kinase. Biochem Biophys Res Commun. 2001;288(1):69-74.

60. Pollak N, Dölle C, Ziegler M. The power to reduce: pyridine nucleotides--small molecules with a multitude of functions. Biochem J. 2007:402(2):205-18

61. Gill DM, Meren R. ADP-ribosylation of membrane proteins catalyzed by cholera toxin: basis of the activation of adenylate cyclase. Proc Natl Acad Sci U S A. 1978;75(7):3050-4

62. Schreiber $V$, et al. Poly (ADP-ribose): novel functions for an old molecule. Nat Rev Mol Cell Biol. 2006;7(7):517-28.

63. Corda D, Di Girolamo M. Functional aspects of protein mono-ADPribosylation. Embo j. 2003;22(9):1953-8.

64. Ziegler M. New functions of a long-known molecule. Emerging roles of NAD in cellular signaling. Eur J Biochem. 2000;267(6):1550-64.

65. Ikeda $M$, et al. Studies on the biosynthesis of nicotinamide adenine dinucleotide. li. A role of picolinic carboxylase in the biosynthesis of nicotinamide adenine dinucleotide from tryptophan in mammals. J Biol Chem. 1965;240:1395-401.

66. Hegyi J, Schwartz RA, Hegyi V. Pellagra: dermatitis, dementia, and diarrhea. Int J Dermatol. 2004:43(1):1-5.

67. Williams RJ, Major RT. THE STRUCTURE OF PANTOTHENIC ACID. Science. 1940;91(2358):246

68. Tahiliani AG, Beinlich CJ. Pantothenic acid in health and disease. Vitam Horm. 1991;46:165-228.

69. Leonardi R, Jackowski S. Biosynthesis of pantothenic acid and Coenzyme A. EcoSal Plus. 2007;2(2). https://doi.org/10.1128/ecosalplus.3.6.3.4.

70. Pettit FH, Pelley JW, Reed $\sqcup$. Regulation of pyruvate dehydrogenase kinase and phosphatase by acetyl-CoA/CoA and NADH/NAD ratios. Biochem Biophys Res Commun. 1975;65(2):575-82.

71. McMinn CL, Ottaway JH. Studies on the mechanism and kinetics of the 2oxoglutarate dehydrogenase system from pig heart. Biochem J. 1977;161(3): 569-81

72. Coon MJ, Robinson WG. Amino acid metabolism. Annu Rev Biochem. 1958; 27(3):561-612.

73. Novelli GD. Metabolic functions of pantothenic acid. Physiol Rev. 1953;33(4): 525-43.

74. Larrabee AR, et al. Acyl carrier protein. V. Identification of 4'phosphopantetheine bound to a mammalian fatty acid synthetase preparation. Proc Natl Acad Sci U S A. 1965;54(1):267-73.

75. Hodges RE, Ohlson MA, Bean WB. Pantothenic acid deficiency in man. J Clin Invest. 1958;37(11):1642-57.

76. Bean WB, Hodges RE, Daum K. Pantothenic acid deficiency induced in human subjects. J Clin Invest. 1955;34(7, Part 1):1073-84.

77. Snell EE. Chemical structure in relation to biological activities of vitamin B6. Vitam Horm. 1958;16:77-125.

78. Hanna MC, Turner AJ, Kirkness EF. Human pyridoxal kinase. cDNA cloning expression, and modulation by ligands of the benzodiazepine receptor. J Biol Chem. 1997;272(16):10756-60.

79. McCormick DB, Chen H. Update on interconversions of vitamin B-6 with its coenzyme. J Nutr. 1999;129(2):325-7.

80. Denner LA, Wu JY. Two forms of rat brain glutamic acid decarboxylase differ in their dependence on free pyridoxal phosphate. J Neurochem. 1985;44(3): 957-65.
81. Bertoldi M. Mammalian Dopa decarboxylase: structure, catalytic activity and inhibition. Arch Biochem Biophys. 2014;546:1-7.

82. Karpeisky MY, Ivanov VI. A molecular mechanism for enzymatic transamination. Nature. 1966:210(5035):493-6.

83. Kabil O, Banerjee R. Redox biochemistry of hydrogen sulfide. J Biol Chem. 2010;285(29):21903-7.

84. Brown BL, et al. Structure of the Mitochondrial Aminolevulinic Acid Synthase, a Key Heme Biosynthetic Enzyme. Structure. 2018;26(4):580-589.e4.

85. Strijbis K, Vaz FM, Distel B. Enzymology of the carnitine biosynthesis pathway. IUBMB Life. 2010;62(5):357-62.

86. Phillips RS. Structure and mechanism of kynureninase. Arch Biochem Biophys. 2014:544:69-74.

87. Bourquin F, Capitani G, Grütter MG. PLP-dependent enzymes as entry and exit gates of sphingolipid metabolism. Protein Sci. 2011;20(9):1492-508.

88. Schirch V, Szebenyi DM. Serine hydroxymethyltransferase revisited. Curr Opin Chem Biol. 2005;9(5):482-7.

89. Helmreich EJ. How pyridoxal 5'-phosphate could function in glycogen phosphorylase catalysis. Biofactors. 1992;3(3):159-72.

90. Wiss O, Weber F. Biochemical pathology of vitamin b6 deficiency. Vitam Horm. 1964;22:495-501.

91. Kassab S, et al. Cognitive dysfunction in diabetic rats is prevented by pyridoxamine treatment. A multidisciplinary investigation. Mol Metab. 2019; 28:107-19.

92. Jung HY, et al. Pyridoxine improves hippocampal cognitive function via increases of serotonin turnover and tyrosine hydroxylase, and its association with CB1 cannabinoid receptor-interacting protein and the CB1 cannabinoid receptor pathway. Biochim Biophys Acta Gen Subj. 2017; 1861(12):3142-53.

93. DeTitta GT, et al. Molecular structure of biotin. Results of two independent crystal structure investigations. J Am Chem Soc. 1976;98(7):1920-6.

94. Balamurugan K, Ortiz A, Said HM. Biotin uptake by human intestinal and liver epithelial cells: role of the SMVT system. Am J Physiol Gastrointest Liver Physiol. 2003;285(1):G73-7.

95. Zeng WQ, et al. Biotin-responsive basal ganglia disease maps to 2q36.3 and is due to mutations in SLC19A3. Am J Hum Genet. 2005;77(1):16-26.

96. Gitlin G, Bayer EA, Wilchek M. Studies on the biotin-binding site of avidin. Lysine residues involved in the active site. Biochem J. 1987;242(3):923-6.

97. Tong L. Structure and function of biotin-dependent carboxylases. Cell Mol Life Sci. 2013;70(5):863-91.

98. Wiedmann $\mathrm{S}$, et al. Clusters of biotin-responsive genes in human peripheral blood mononuclear cells. J Nutr Biochem. 2004;15(7):433-9.

99. Ingaramo M, Beckett D. Selectivity in post-translational biotin addition to five human carboxylases. J Biol Chem. 2012;287(3):1813-22.

100. Eakin RE, McKinley WA, Williams RJ. Egg-white injury in chicks and its relationship to a deficiency of vitamin h (biotin). Science. 1940; 92(2384):224-5

101. Stokstad EL, Koch J. Folic acid metabolism. Physiol Rev. 1967;47(1):83-116.

102. Fox JT, Stover PJ. Folate-mediated one-carbon metabolism. Vitam Horm. 2008;79:1-44.

103. Tibbetts AS, Appling DR. Compartmentalization of Mammalian folatemediated one-carbon metabolism. Annu Rev Nutr. 2010;30:57-81.

104. Ducker GS, Rabinowitz JD. One-Carbon Metabolism in Health and Disease. Cell Metab. 2017;25(1):27-42

105. Lucock M. Folic acid: nutritional biochemistry, molecular biology, and role in disease processes. Mol Genet Metab. 2000;71(1-2):121-38.

106. Stover PJ, Durga J, Field MS. Folate nutrition and blood-brain barrier dysfunction. Curr Opin Biotechnol. 2017;44:146-52.

107. Lewis CA, et al. Tracing compartmentalized NADPH metabolism in the cytosol and mitochondria of mammalian cells. Mol Cell. 2014;55(2):253-63.

108. Steinberg SE. Mechanisms of folate homeostasis. Am J Physiol. 1984;246(4 Pt 1):G319-24

109. Green R, Datta Mitra A. Megaloblastic Anemias: Nutritional and Other Causes. Med Clin North Am. 2017;101(2):297-317.

110. Pitkin RM. Folate and neural tube defects. Am J Clin Nutr. 2007:85(1): $285 \mathrm{~s}-8 \mathrm{~s}$.

111. Blom HJ, Smulders Y. Overview of homocysteine and folate metabolism. With special references to cardiovascular disease and neural tube defects. J Inherit Metab Dis. 2011;34(1):75-81.

112. Ueland PM, et al. The controversy over homocysteine and cardiovascular risk. Am J Clin Nutr. 2000;72(2):324-32. 
113. Mattson MP, Shea TB. Folate and homocysteine metabolism in neural plasticity and neurodegenerative disorders. Trends Neurosci. 2003; 26(3):137-46.

114. Sharma M, Tiwari M, Tiwari RK. Hyperhomocysteinemia: Impact on Neurodegenerative Diseases. Basic Clin Pharmacol Toxicol. 2015;117(5): 287-96.

115. Shen L, Ji HF. Associations between Homocysteine, Folic Acid, Vitamin B12 and Alzheimer's Disease: Insights from Meta-Analyses. J Alzheimers Dis. 2015;46(3):777-90.

116. Troesch B, Weber $\mathrm{P}$, Mohajeri MH. Potential links between impaired onecarbon metabolism due to polymorphisms, inadequate b-vitamin status, and the development of alzheimer's disease. Nutrients. 2016;8(12):803.

117. Duthie SJ. Folate and cancer: how DNA damage, repair and methylation impact on colon carcinogenesis. J Inherit Metab Dis. 2011;34(1):101-9.

118. Mason JB. Unraveling the complex relationship between folate and cancer risk. Biofactors. 2011;37(4):253-60.

119. Zhao $Y$, et al. Folate intake, serum folate levels and esophageal cancer risk: an overall and dose-response meta-analysis. Oncotarget. 2017:8(6):10458-69.

120. Twigt $J M$, et al. Preconception folic acid use influences the follicle fluid proteome. Eur J Clin Invest. 2015;45(8):833-41.

121. Leclerc $D$, et al. Quantitative proteomics reveals differentially expressed proteins in murine preneoplastic intestine in a model of intestinal tumorigenesis induced by low dietary folate and MTHFR deficiency. Proteomics. 2014;14(21-22):2558-65.

122. Gerard N, et al. Proteomic analysis identifies cytoskeleton-interacting proteins as major downstream targets of altered folate status in the aorta of adult rat. Mol Nutr Food Res. 2014;58(12):2307-19.

123. Chanson A, et al. Proteomic analysis reveals changes in the liver protein pattern of rats exposed to dietary folate deficiency. J Nutr. 2005;135(11): 2524-9.

124. Rattanasinganchan $P$, et al. A folic acid-induced rat model of renal injury to identify biomarkers of tubulointerstitial fibrosis from urinary exosomes. Asian Biomedicine. 2017;10(5):491-502.

125. Duthie SJ, et al. Blood folate status and expression of proteins involved in immune function, inflammation, and coagulation: biochemical and proteomic changes in the plasma of humans in response to long-term synthetic folic acid supplementation. J Proteome Res. 2010;9(4):1941-50.

126. Xu Y, Tang Y, Li Y. Effect of folic acid on prenatal alcohol-induced modification of brain proteome in mice. Br J Nutr. 2008;99(3):455-61.

127. McNeil CJ, et al. Disruption of lipid metabolism in the liver of the pregnant rat fed folate-deficient and methyl donor-deficient diets. Br J Nutr. 2008; 99(2):262-71.

128. McNeil CJ, et al. Maternal diets deficient in folic acid and related methyl donors modify mechanisms associated with lipid metabolism in the fetal liver of the rat. Br J Nutr. 2009;102(10):1445-52

129. Lan W, et al. A density-based proteomics sample fractionation technology: folate deficiency induced oxidative stress response in liver and brain. J Biomol Tech. 2007;18(4):213-25.

130. Liu J, et al. Effect of maternal folic acid supplementation on hepatic proteome in newborn piglets. Nutrition. 2013;29(1):230-4.

131. Hodgkin DC, et al. Structure of vitamin B12. Nature. 1956:178(4524):64-6.

132. Seetharam B, Alpers DH. Absorption and transport of cobalamin (vitamin B12). Annu Rev Nutr. 1982;2:343-69.

133. Bauer JA. Synthesis, characterization and nitric oxide release profile of nitrosylcobalamin: a potential chemotherapeutic agent. Anticancer Drugs. 1998;9(3):239-44.

134. Banerjee RV, Matthews RG. Cobalamin-dependent methionine synthase. Faseb j. 1990;4(5):1450-9

135. Thomä NH, Leadlay PF. Mechanistic and structural studies on methylmalonyl-CoA mutase. Biochem Soc Trans. 1998;26(3):293-8

136. Nixon PF, Bertino JR. Interrelationships of vitamin B12 and folate in man. Am J Med. 1970;48(5):555-61.

137. Lindenbaum J, et al. Neuropsychiatric disorders caused by cobalamin deficiency in the absence of anemia or macrocytosis. N Engl J Med. 1988; 318(26):1720-8.

138. Caterino $\mathrm{M}$, et al. The proteome of cblC defect: in vivo elucidation of altered cellular pathways in humans. J Inherit Metab Dis. 2015;38(5):969-79.

139. Gianazza E, et al. Cobalamin (vitamin B12)-deficiency-induced changes in the proteome of rat cerebrospinal fluid. Biochem J. 2003;374(Pt 1):239-46.

140. Ahmad S, et al. Maternal micronutrient deficiency leads to alteration in the kidney proteome in rat pups. J Proteomics. 2015;127(Pt A):178-84.
141. Ahmad S, et al. PPAR signaling pathway is a key modulator of liver proteome in pups born to vitamin B (12) deficient rats. J Proteomics. 2013; 91:297-308.

142. Bürzle $M$, et al. The sodium-dependent ascorbic acid transporter family SLC23. Mol Aspects Med. 2013;34(2-3):436-54.

143. Wilson JX. Regulation of vitamin C transport. Annu Rev Nutr. 2005;25: 105-25.

144. Winkler BS, Orselli SM, Rex TS. The redox couple between glutathione and ascorbic acid: a chemical and physiological perspective. Free Radic Biol Med. 1994;17(4):333-49.

145. May JM, et al. Reduction of dehydroascorbate to ascorbate by the selenoenzyme thioredoxin reductase. J Biol Chem. 1997;272(36):22607-10.

146. Myllylä R, et al. Ascorbate is consumed stoichiometrically in the uncoupled reactions catalyzed by prolyl 4-hydroxylase and lysyl hydroxylase. J Biol Chem. 1984;259(9):5403-5.

147. de Jong L, Albracht SP, Kemp A. Prolyl 4-hydroxylase activity in relation to the oxidation state of enzyme-bound iron. The role of ascorbate in peptidyl proline hydroxylation. Biochim Biophys Acta. 1982;704(2):326-32.

148. Fong GH, Takeda K. Role and regulation of prolyl hydroxylase domain proteins. Cell Death Differ. 2008;15(4):635-41.

149. Gjaltema RA, R.A. Bank. Molecular insights into prolyl and lysyl hydroxylation of fibrillar collagens in health and disease. Crit Rev Biochem Mol Biol. 2017; 52(1):74-95.

150. Passoja K, et al. Cloning and characterization of a third human lysyl hydroxylase isoform. Proc Natl Acad Sci U S A. 1998;95(18):10482-6.

151. Henderson LM, Nelson PJ, Henderson L. Mammalian enzymes of trimethyllysine conversion to trimethylaminobutyrate. Fed Proc. 1982;41(12):2843-7.

152. Longo N, Frigeni M, Pasquali M. Carnitine transport and fatty acid oxidation. Biochim Biophys Acta. 2016;1863(10):2422-35.

153. May JM, Qu ZC, Meredith ME. Mechanisms of ascorbic acid stimulation of norepinephrine synthesis in neuronal cells. Biochem Biophys Res Commun. 2012:426(1):148-52.

154. Meister A. On the antioxidant effects of ascorbic acid and glutathione. Biochem Pharmacol. 1992;44(10):1905-15.

155. Hemilä H. Vitamin C and infections. Nutrients. 2017;9(4):339.

156. Cudjoe EK Jr, et al. Temporal map of the pig polytrauma plasma proteome with fluid resuscitation and intravenous vitamin C treatment. J Thromb Haemost. 2019;17(11):1827-37.

157. Aumailley $L$, et al. Vitamin $C$ alters the amount of specific endoplasmic reticulum associated proteins involved in lipid metabolism in the liver of mice synthesizing a nonfunctional Werner syndrome (Wrn) mutant protein. PLoS One. 2018;13(3):e0193170.

158. Motorykin I, et al. Proteome-driven elucidation of adaptive responses to combined vitamin E and C deficiency in zebrafish. J Proteome Res. 2014; 13(3):1647-56

159. Da Costa LA, et al. Association between the plasma proteome and serum ascorbic acid concentrations in humans. J Nutr Biochem. 2013:24(5):842-7.

160. Park S, et al. Proteomic analysis reveals upregulation of RKIP in S-180 implanted BALB/C mouse after treatment with ascorbic acid. J Cell Biochem. 2009;106(6):1136-45.

161. Lee J, et al. Proteomic analysis of tumor tissue in CT-26 implanted BALB/C mouse after treatment with ascorbic acid. Cell Mol Biol Lett. 2012;17(1):62-76.

162. Weissinger EM, et al. Effects of oral vitamin C supplementation in hemodialysis patients: a proteomic assessment. Proteomics. 2006;6(3): 993-1000.

163. Henry HL, Norman AW. Vitamin D: metabolism and biological actions. Annu Rev Nutr. 1984:4:493-520.

164. Bikle DD. Vitamin D metabolism, mechanism of action, and clinical applications. Chem Biol. 2014;21(3):319-29.

165. Glossmann HH. Origin of 7-dehydrocholesterol (provitamin D) in the skin. J Invest Dermatol. 2010;130(8):2139-41.

166. Jones G, Prosser DE, Kaufmann M. Cytochrome P450-mediated metabolism of vitamin D. J Lipid Res. 2014;55(1):13-31.

167. White $P$, Cooke $N$. The multifunctional properties and characteristics of vitamin D-binding protein. Trends Endocrinol Metab. 2000;11(8):320-7.

168. Holick MF, DeLuca HF. Chemistry and biological activity of vitamin D, its metabolites and analogs. Adv Steroid Biochem Pharmacol. 1974:4(0):111-55.

169. Haussler MR, et al. Vitamin D receptor (VDR)-mediated actions of 1alpha,25(OH)(2) vitamin D (3): genomic and non-genomic mechanisms. Best Pract Res Clin Endocrinol Metab. 2011;25(4):543-59. 
170. Lips P. Vitamin D physiology. Prog Biophys Mol Biol. 2006;92(1):4-8.

171. Goltzman D. Functions of vitamin D in bone. Histochem Cell Biol. 2018; 149(4):305-12

172. Nemere I, et al. Ribozyme knockdown functionally links a 1,25(OH)2D3 membrane binding protein (1,25D3-MARRS) and phosphate uptake in intestinal cells. Proc Natl Acad Sci U S A. 2004;101(19):7392-7.

173. Hii CS, Ferrante A. The Non-Genomic Actions of Vitamin D. Nutrients. 2016 8(3):135.

174. Holick MF. Vitamin D deficiency. N Engl J Med. 2007;357(3):266-81.

175. Faridi KF, et al. Vitamin D deficiency and non-lipid biomarkers of cardiovascular risk. Arch Med Sci. 2017;13(4):732-7.

176. Kheiri B, et al. Vitamin D deficiency and risk of cardiovascular diseases: a narrative review. Clin Hypertens. 2018;24:9.

177. Dimitrakopoulou Vl, et al. Circulating vitamin D concentration and risk of seven cancers: Mendelian randomisation study. Bmj. 2017;359:j4761.

178. Hossain S, et al. Vitamin D and breast cancer: A systematic review and metaanalysis of observational studies. Clin Nutr ESPEN. 2019;30:170-84

179. Littlejohns TJ, et al. Vitamin D and the risk of dementia and Alzheimer disease. Neurology. 2014;83(10):920-8.

180. Moretti R, Morelli ME, Caruso P. Vitamin D in neurological diseases: a rationale for a pathogenic impact. Int J Mol Sci. 2018;19(8):2245.

181. Ishikawa LLW, et al. Vitamin D Deficiency and Rheumatoid Arthritis. Clin Rev Allergy Immunol. 2017;52(3):373-88

182. Pierrot-Deseilligny C, Souberbielle JC. Vitamin D and multiple sclerosis: An update. Mult Scler Relat Disord. 2017:14:35-45.

183. Chen $L$, et al. Identification of vitamin $D$ sensitive pathways during lung development. Respir Res. 2016:17:47.

184. Oveland E, et al. 1,25-Dihydroxyvitamin-D3 induces brain proteomic changes in cuprizone mice during remyelination involving calcium proteins. Neurochem Int. 2018;112:267-77.

185. West KP Jr, et al. A Plasma alpha-Tocopherome Can Be Identified from Proteins Associated with Vitamin E Status in School-Aged Children of Nepal. J Nutr. 2015;145(12):2646-56.

186. Hamezah HS, et al. Modulation of Proteome Profile in AbetaPP/PS1 Mice Hippocampus, Medial Prefrontal Cortex, and Striatum by Palm Oil Derived Tocotrienol-Rich Fraction. J Alzheimers Dis. 2019;72(1):229-46.

187. Lee SE, et al. Biological Systems of Vitamin K: A Plasma Nutriproteomics Study of Subclinical Vitamin K Deficiency in 500 Nepalese Children. OMICS. 2016;20(4):214-23.

188. Al-Daghri NM, et al. Sex-specific vitamin D effects on blood coagulation among overweight adults. Eur J Clin Invest. 2016;46(12):1031-40.

189. Walker GE, et al. Pediatric obesity and vitamin D deficiency: a proteomic approach identifies multimeric adiponectin as a key link between these conditions. PLoS One. 2014;9(1):e83685.

190. Walker GE, et al. Fetuin B links vitamin D deficiency and pediatric obesity: Direct negative regulation by vitamin D. J Steroid Biochem Mol Biol. 2018;182:37-49.

191. Jung SH, et al. The serum protein fetuin-B is involved in the development of acute myocardial infarction. Clin Sci (Lond). 2015;129(1):27-38.

192. Wang QQ, Zhao X, Pu XP. Proteome analysis of the left ventricle in the vitamin D (3) and nicotine-induced rat vascular calcification model. J Proteomics. 2011;74(4):480-9.

193. Almofti MR, et al. Proteomic analysis of rat aorta during atherosclerosis induced by high cholesterol diet and injection of vitamin D3. Clin Exp Pharmacol Physiol. 2006;33(4):305-9.

194. Almeras L, et al. Developmental vitamin D deficiency alters brain protein expression in the adult rat: implications for neuropsychiatric disorders. Proteomics. 2007;7(5):769-80.

195. Keeney JTR, et al. Dietary vitamin D deficiency in rats from middle to old age leads to elevated tyrosine nitration and proteomics changes in levels of key proteins in brain: implications for low vitamin D-dependent age-related cognitive decline. Free Radic Biol Med. 2013;65:324-34

196. Herrera E, Barbas C. Vitamin E: action, metabolism and perspectives. J Physiol Biochem. 2001;57(1):43-56.

197. Kamal-Eldin A, Appelqvist LA. The chemistry and antioxidant properties of tocopherols and tocotrienols. Lipids. 1996;31(7):671-701.

198. Brigelius-Flohe R. Bioactivity of vitamin E. Nutr Res Rev. 2006;19(2):174-86.

199. Zingg JM. Vitamin E: A Role in Signal Transduction. Annu Rev Nutr. 2015;35:135-73

200. Schneider C. Chemistry and biology of vitamin E. Mol Nutr Food Res. 2005; 49(1):7-30.
201. Di Donato I, Bianchi S, Federico A. Ataxia with vitamin E deficiency: update of molecular diagnosis. Neurol Sci. 2010;31(4):511-5.

202. Sitrin MD, et al. Vitamin E deficiency and neurologic disease in adults with cystic fibrosis. Ann Intern Med. 1987;107(1):51-4.

203. Gomez-Pomar E, et al. Vitamin E in the Preterm Infant: A Forgotten Cause of Hemolytic Anemia. Am J Perinatol. 2018:35(3):305-10.

204. Muller DP. Vitamin E and neurological function. Mol Nutr Food Res. 2010; 54(5):710-8.

205. Ulatowski LM, Manor D. Vitamin E and neurodegeneration. Neurobiol Dis. 2015;84:78-83.

206. Kaga $E$, et al. Identification of differentially expressed proteins in atherosclerotic aorta and effect of vitamin E. J Proteomics. 2013;92:260-73.

207. Panachan J, et al. Differentially expressed plasma proteins of betathalassemia/hemoglobin E patients in response to curcuminoids/vitamin E antioxidant cocktails. Hematology. 2019:24(1):300-7.

208. Aldred S, et al. Alpha tocopherol supplementation elevates plasma apolipoprotein A1 isoforms in normal healthy subjects. Proteomics. 2006: 6(5):1695-703

209. Naderi $M$, et al. Proteomic analysis of liver tissue from rainbow trout (Oncorhynchus mykiss) under high rearing density after administration of dietary vitamin E and selenium nanoparticles. Comp Biochem Physiol Part D Genomics Proteomics. 2017;22:10-9.

210. Kim J, et al. Changes in serum proteomic patterns by presurgical alphatocopherol and L-selenomethionine supplementation in prostate cancer Cancer Epidemiol Biomarkers Prev. 2005:14(7):1697-702.

211. Shearer MJ, Vitamin K. Lancet. 1995;345(8944):229-34.

212. Stafford DW. The vitamin K cycle. J Thromb Haemost. 2005:3(8):1873-8.

213. Berkner KL, Runge KW. The physiology of vitamin K nutriture and vitamin Kdependent protein function in atherosclerosis. J Thromb Haemost. 2004 2(12):2118-32

214. Shearer MJ. Vitamin K deficiency bleeding (VKDB) in early infancy. Blood Rev. 2009;23(2):49-59.

215. Greer FR. Vitamin K deficiency and hemorrhage in infancy. Clin Perinatol. 1995:22(3):759-77.

216. Johansson $\mathrm{HJ}$, et al. Breast cancer quantitative proteome and proteogenomic landscape. Nat Commun. 2019;10(1):1600.

217. Zhu Y, et al. Discovery of coding regions in the human genome by integrated proteogenomics analysis workflow. Nat Commun. 2018;9(1):903.

218. Müller JB, et al. The proteome landscape of the kingdoms of life. Nature. 2020:582(7813):592-6.

219. Meier F, et al. BoxCar acquisition method enables single-shot proteomics at a depth of 10,000 proteins in 100 minutes. Nat Methods. 2018;15(6):440-8.

220. Lundby $A$, et al. Proteomic analysis of lysine acetylation sites in rat tissues reveals organ specificity and subcellular patterns. Cell Rep. 2012; 2(2):419-31

221. Keshishian $\mathrm{H}$, et al. Quantitative, multiplexed assays for low abundance proteins in plasma by targeted mass spectrometry and stable isotope dilution. Mol Cell Proteomics. 2007:6(12):2212-29.

222. Pernemalm M, et al. In-depth human plasma proteome analysis captures tissue proteins and transfer of protein variants across the placenta. Elife. 2019;8:e41608

223. Hogrebe $A$, et al. Benchmarking common quantification strategies for largescale phosphoproteomics. Nat Commun. 2018;9(1):1045.

224. Panizza $\mathrm{E}$, et al. Isoelectric point-based fractionation by HiRIEF coupled to LC-MS allows for in-depth quantitative analysis of the phosphoproteome. Sci Rep. 2017;7(1):4513.

225. Orre LM, et al. SubCellBarCode: Proteome-wide Mapping of Protein Localization and Relocalization. Mol Cell. 2019;73(1):166-82 e7.

226. Tamborero D, et al. Support systems to guide clinical decision-making in precision oncology: The Cancer Core Europe Molecular Tumor Board Portal. Nat Med. 2020:26(7):992-4.

227. Vacanti NM. The Fundamentals of Constructing and Interpreting Heat Maps. Methods Mol Biol. 2019:1862:279-91.

228. Chen EY, et al. Enrichr: interactive and collaborative HTML5 gene list enrichment analysis tool. BMC Bioinformatics. 2013:14:128.

229. Kuleshov MV, et al. Enrichr: a comprehensive gene set enrichment analysis web server 2016 update. Nucleic Acids Res. 2016:44(W1):W90-7.

230. Huang da W, Sherman BT, Lempicki RA. Systematic and integrative analysis of large gene lists using DAVID bioinformatics resources. Nat Protoc. 2009; 4(1):44-57. 
231. Huang da W, Sherman BT, Lempicki RA. Bioinformatics enrichment tools: paths toward the comprehensive functional analysis of large gene lists. Nucleic Acids Res. 2009;37(1):1-13.

232. Subramanian A, et al. Gene set enrichment analysis: a knowledge-based approach for interpreting genome-wide expression profiles. Proc Natl Acad Sci U S A. 2005;102(43):15545-50.

233. Eden $\mathrm{E}$, et al. Discovering motifs in ranked lists of DNA sequences. PLoS Comput Biol. 2007;3(3):e39.

234. Eden E, et al. GOrilla: a tool for discovery and visualization of enriched GO terms in ranked gene lists. BMC Bioinformatics. 2009;10:48.

235. Gropper SS, Smith JL, Groff JL. Advanced Nutrition and Human Metabolism. 6th ed: Cengage Learning; 2012.

236. Michal G, Schomburg D. Biochemical Pathways. 2nd ed: Wiley; 2012.

237. Kanehisa M, Goto S. KEGG: kyoto encyclopedia of genes and genomes. Nucleic Acids Res. 2000;28(1):27-30.

\section{Publisher's Note}

Springer Nature remains neutral with regard to jurisdictional claims in published maps and institutional affiliations.

Ready to submit your research? Choose BMC and benefit from:

- fast, convenient online submission

- thorough peer review by experienced researchers in your field

- rapid publication on acceptance

- support for research data, including large and complex data types

- gold Open Access which fosters wider collaboration and increased citations

- maximum visibility for your research: over $100 \mathrm{M}$ website views per year

At BMC, research is always in progress.

Learn more biomedcentral.com/submissions 